\title{
Personal Exposure Rates as a Function of Reactor Power
}

\author{
Pao-Shan $\mathrm{WENG}^{* 1}$ and Pin-Chieh $\mathrm{HsU}^{* 2}$
}

(Received March 20, 1986)

(Accepted May 19, 1986)

KEY WORDS: $\mathrm{CaSO}_{4}$ : Dy, organ, Rando phantom, reactor, TLD, total body

\section{INTRODUCTION}

The versatility of a swimming pool reactor for educational and research purposes such as the Tsing Hua Openpool Reactor (THOR) leads to a variation in environmental radiation not only in times but also in places where several experiments are carried out. The exposure or dose rates thus incurred in the reactor building are of interest and concern. Though film or TL badges and various types of survey instruments are used in routine monitoring, it is essential to study the organ doses that the workers receive as a function of reactor power at the periphery where most experiments are performed. This topic will be dealt with hereinafter.

\section{MATERIALS AND METHODS}

A Rando phantom was used to simulate the worker though it is specially designed for radiotherapy purposes. A brief description is given in elsewhere. ${ }^{1)}$ The dosimeter used was the selffabricated thermoluminescent dosimeters (TLDs) $\mathrm{CaSO}_{4}$ : Dy and was also described in the previous paper given by the authors. ${ }^{2}$ The TLD $\mathrm{CaSO}_{4}$ : Dy powder of $80 \mathrm{mg}$ was encapsulated in a black polyethylene capsule with $3 \mathrm{~mm}$ internal diameter, $1 \mathrm{~mm}$ wall thickness and $20 \mathrm{~mm}$ length. For each reading $17.25 \pm 0.40 \mathrm{mg}$ of the $\mathrm{CaSO}_{4}$ : Dy powder were taken. The TL was measured with the Harshaw 2000 B\&C TLD reader.

*1 Institute of Nuclear Science, National Tsing Hua University, Hsinchu 30043, Taiwan, R.O.C.

*2 Nuclear Science and Technology Development Center, National Tsing Hua University, Hsinchu 30043, Taiwan, R.O.C.
To study the dose distribution in organs, the TLD capsules were placed in the slots in the Rando phantom for a more realistic measure of organ dose. The phantom provides several slots for inserting TLD capsultes in a matrix form of $3 \mathrm{~cm} \times$ $3 \mathrm{~cm}$. The TLD capsules were also placed on the body surface of the phantom.

The sites of measurement in THOR are shown in Fig. 1 where the radiation levels were high as surveyed by the health physics group. They were on the bridge which lies across the pool, and outside the thermal column and beam port in the reactor bay area. On the bridge several vertical tubes were installed for sample irradiation. The thermal column was used for neutron radiography and biological sample irradiation. The beam port was used for prompt $\gamma$ neutron activation analysis. They were accessible by the faculty members and students.

The locations of TLDs on the body surface of the Rando phantom are shown in Fig. 2 with reference to eyes, thyroids, gonad, and spine. Inside the Rando phantom, the TLDs were placed in lung and abdomen as shown in Fig. 3. In addition, four TLDs were placed around the waist.

\section{RESULTS AND DISCUSSION}

The $\gamma$-ray spectrum on the bridge was measured at the same time as this experiment was going on. The radionuclides detected from the $\gamma$-ray spectrum using a $\mathrm{Ge}(\mathrm{Li})$ detector revealed the fact that they are very similar to those detected in the discharge from the nuclear power plant. Both corrosion and fission products commonly found and known in a nuclear power plant were detected on the bridge. Since the response of $\mathrm{TLD} \mathrm{CaSO} \mathrm{CaS}_{4}: \mathrm{Dy}$ is 


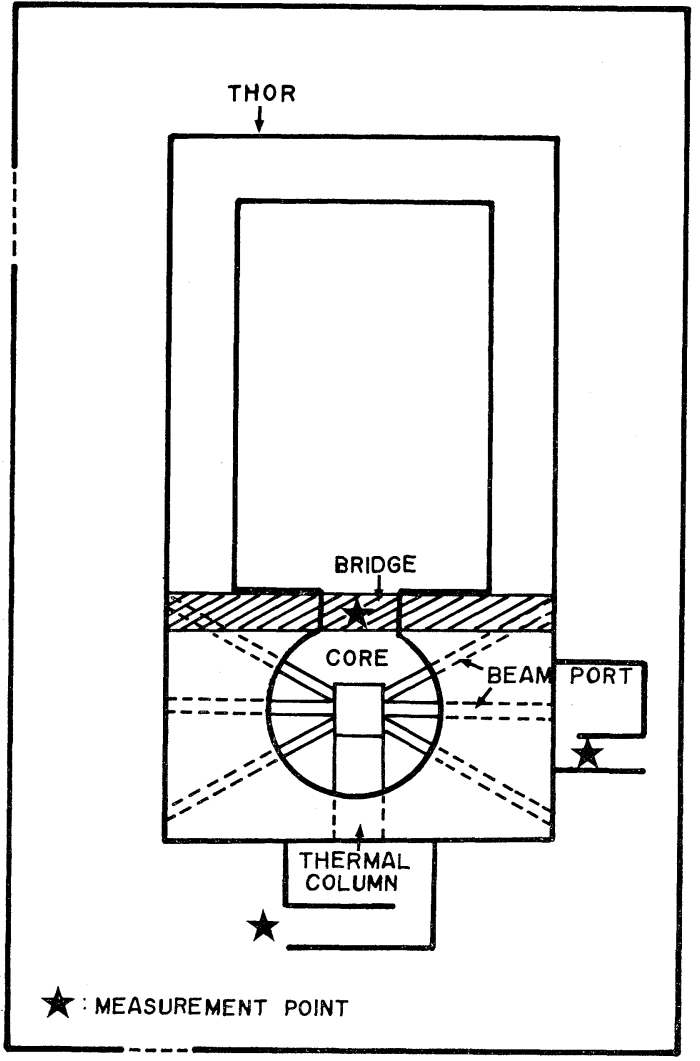

Fig. 1 Measuring sites at the Tsing Hua Openpool Reactor.
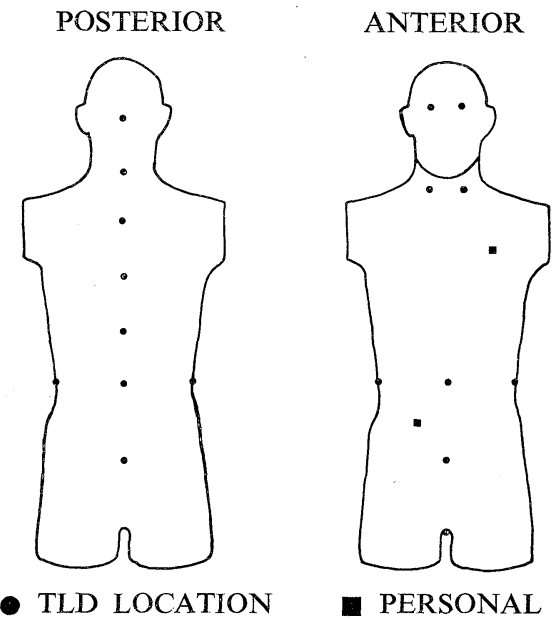

PERSONAL DOSIMETERS

Fig. 2 Locations of TLDs on the surface of the Rando phantom.

energy dependent, the range of $\gamma$-ray energies should be known for TLD calibration. Within the energy range of the radionuclides detected, the dependence of energy is not existent.

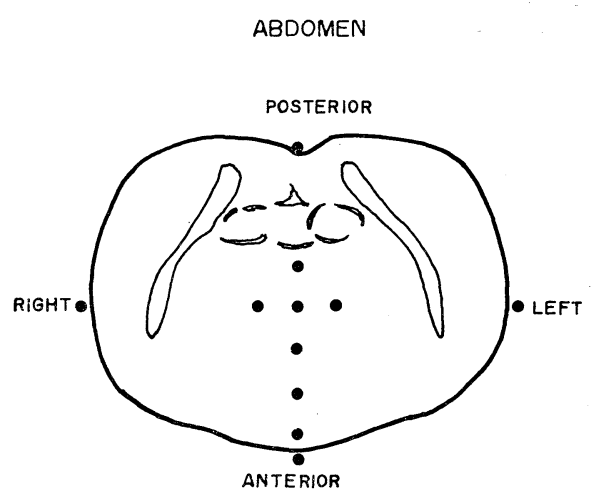

- TLD location

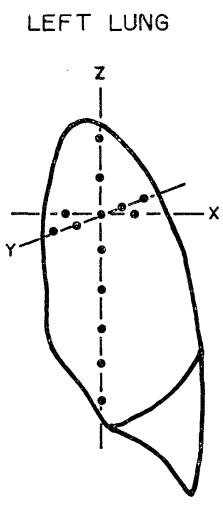

- : TLD LOCATION

Fig. 3 Locations of TLDs inside the Rando phantom.

The exposure rates on the bridge for gonads of male and female, eyes, thyroids, lungs, and total body as a function of reactor power are shown in Fig. 4. The increase in exposure rates are quite linear for total body, eyes, thyroids, and lungs. For the gonads of both sex, the exposure rates are not so linear. Since the gonads of both sex are close to the floor, they receive the highest exposure rates as a single organ is concerned.

In abdomen, the decrease in exposure rates with depth and reactor is shown in Fig. 5. At higher power levels such as 800 and $600 \mathrm{~kW}$, the decrease in exposure rates is rather rapidly from the surface to $2 \mathrm{~cm}$ depth, but is not so significant at lower reactor power as 400 and $200 \mathrm{~kW}$. At higher levels, more capture $\gamma$ rays are expected. Their energies mostly lie in the lower energy region which causes the higher response of TLD $\mathrm{CaSO}_{4}$ : Dy on the phantom surface and yet attenuates more rapidly inside the phantom at the first few centime- 


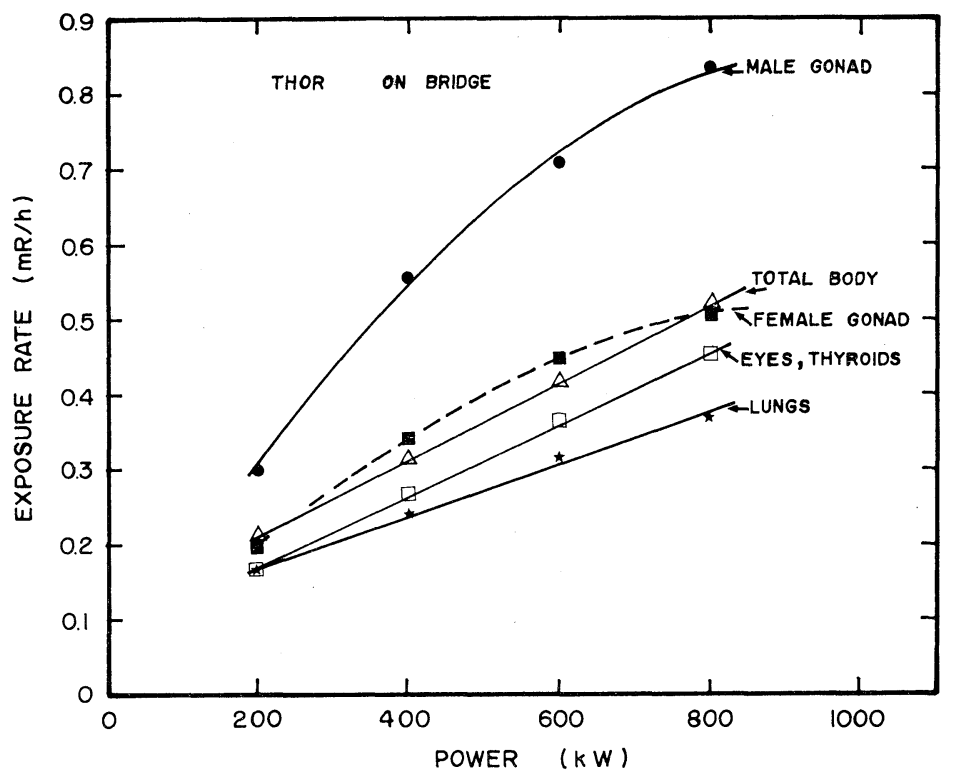

Fig. 4 Exposure rates as function of reactor power for eyes, thyroids, lungs, gonads of both sex, and total body.

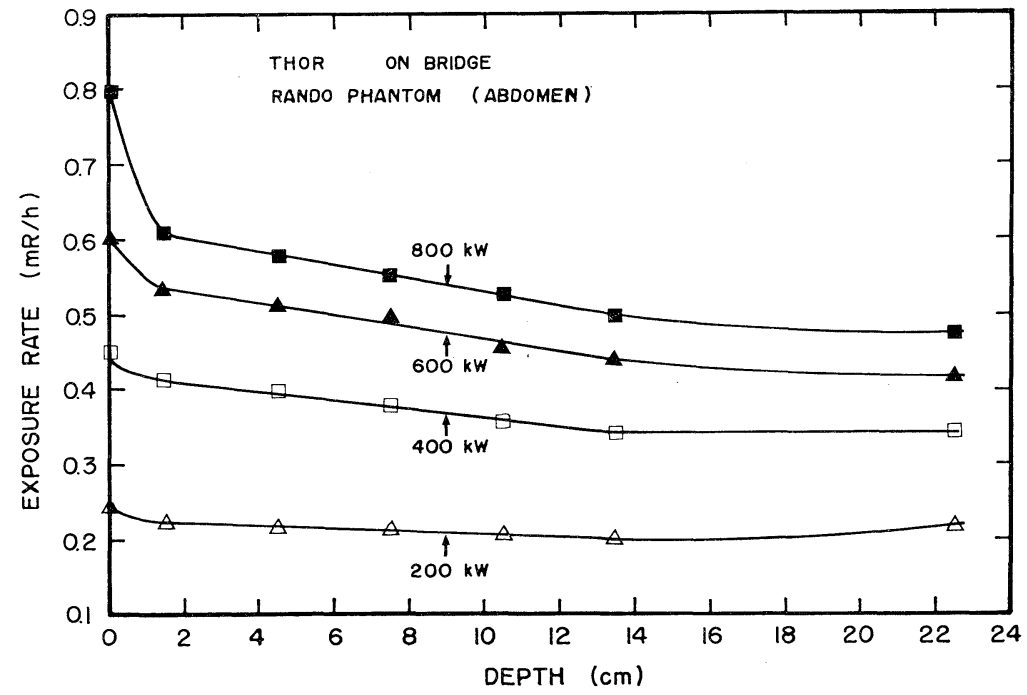

Fig. 5 Exposure rates inside the Rando phantom at abdomen for various reactor power. The origin is on the phantom surface.

ters. On the contrary, at lower power levels, there are very few capture $\gamma$ rays.

In the spine, the increase in exposure rates is very linear no matter the reactor power is high or low as shown in Fig. 6.

In conclusion, the relationship between power levels of a swimming-pool type reactor and the exposure rates received using a phantom to simulate radiation worker is very linear as far as total body is concerned.

ACKNOWLEDGMENTS: The financial support from the Atomic Energy Council of Executive Yuan, R.O.C. is highly appreciated. 


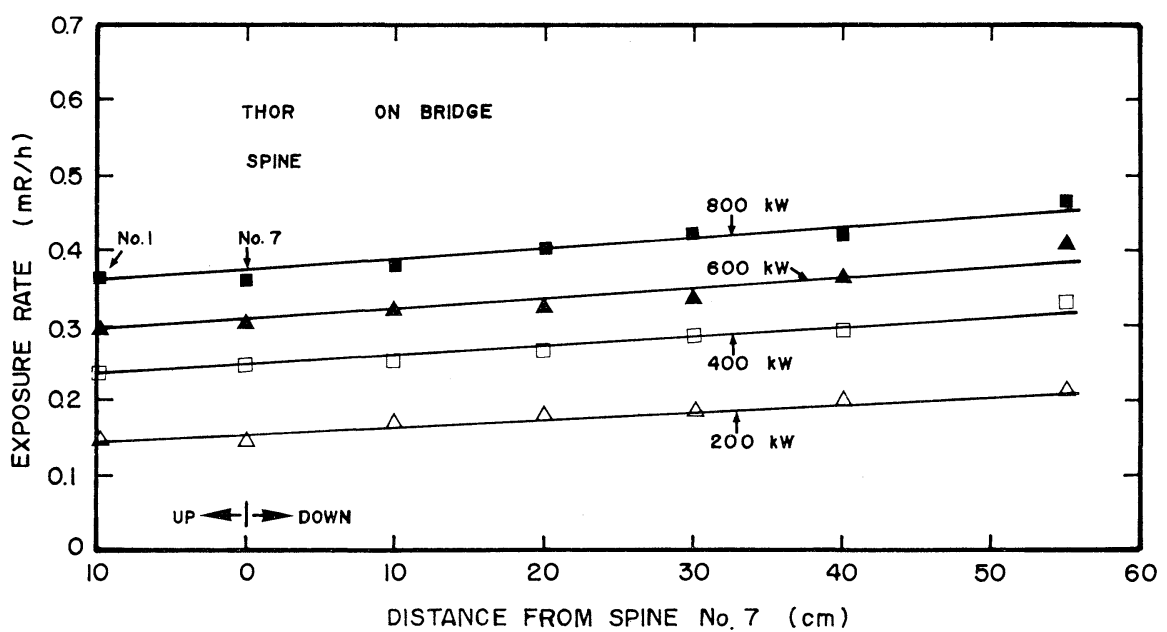

Fig. 6 Exposure rates along the spine as a function of reactor power. The starting point of distance is at spin No. 7 .

\section{REFERENCES}

1) Y.S. YAu, S.C. HuANG, P.C. Hsu and P.S. Weng; Gonadal dose obtained from treatment of nasal carcinoma by ionizing radiation, Radiat. Res., 86,
147 (1981).

2) L.N. Su, P.C. Hsu and P.S. Weng; Survey of dose distribution in patients due to operation of CT machines, Hoken Butsuri, 20, 275 (1985). 